\title{
Roberto Schwarz e a sociologia paulista dos anos 1960
}

[ Roberto Schwarz and São Paulo's sociology in the I960s

\section{Karim Helayel ${ }^{\mathbf{x}}$}

\section{Antonio Brasil Jr. ${ }^{2}$}

RESUMO. $\mathrm{O}$ artigo apresenta a hipótese de que, ao identificar a "volubilidade" como princípio formal do romance Memórias póstumas de Brás Cubas, de Machado de Assis, Roberto Schwarz estaria se posicionando frente às divergências entre Maria Sylvia de Carvalho Franco e Fernando Henrique Cardoso em torno da mobilização da categoria "patrimonialismo". Localizaremos o argumento de Um mestre na periferia do capitalismo (I990), de Schwarz, diante das críticas de Franco ao uso por ela considerado improcedente da categoria "patrimonialismo" por parte de Cardoso. Discutiremos ainda as relações entre o princípio formal da "volubilidade" com a categoria "dilema", proposta por Florestan Fernandes em seus trabalhos. P PALAVRAS-CHAVE - Roberto Schwarz; Florestan Fernandes; Fernando Henrique Cardoso; Maria Sylvia de Carvalho
Franco; patrimonialismo. · ABSTRACT $\cdot$ This contribution presents the hypothesis that, by identifying the "volubility" as a formal principle of Memórias póstumas de Brás Cubas, by Machado de Assis, Roberto Schwarz takes a position in the frame of the divergences between Maria Sylvia de Carvalho Franco and Fernando Henrique Cardoso in connection with the category "patrimonialism". We place our argument on Um mestre na periferia do capitalismo (I990), by Schwarz, against the criticisms by Franco on the use she considers unfounded of the category "patrimonialism" adopted by Cardoso. We shall also discuss the relations between the formal principle of "volubility" and the category "dilema", as proposed by Florestan Fernandes in his works. - KEYWORDS · Roberto Schwarz; Florestan Fernandes; Fernando Henrique Cardoso; Maria Sylvia de Carvalho Franco; patrimonialism.

Recebido em I2 de abril de 2019

Aprovado em 24 de outubro de 2019

HELAYEL, Karim; BRASIL JR., Antonio. Roberto Schwarz e a sociologia paulista dos anos I960. Revista do Instituto de Estudos Brasileiros, Brasil, n. 74, p. 97-II8, dez. 2019.

\section{(C) $(1) \Theta$}

DOI: http://dx.doi.org/Io.II606/issn.23I6-90IX.voi74p97-II8

I Universidade Federal do Rio de Janeiro (UFRJ, Rio de Janeiro, RJ, Brasil).

2 Universidade Federal do Rio de Janeiro (UFRJ, Rio de Janeiro, RJ, Brasil). 
Como admitido em diferentes oportunidades pelo crítico literário Roberto Schwarz, seus trabalhos sobre a obra de Machado de Assis não podem ser entendidos sem a referência ao contexto mais amplo de revisão das interpretações da sociedade brasileira, em particular ao debate que se organizou na Universidade de São Paulo (USP) entre os anos I950-I960. É bem verdade que seus contatos, ainda como estudante de graduação, com Antonio Candido 3 - quem o incentivou para migrar das ciências sociais para a área de letras (SCHWARZ, 20I2b) -, bem como a incorporação precoce do repertório sociológico e crítico da "tradição contraditória" que reúne Lukács, Adorno, Benjamin e Brecht (SCHWARZ, 200ob) pesaram fortemente em suas formulações sobre os processos não lineares de acumulação literária no país ao longo do século XIX. Porém, sem levar em consideração seu acerto de contas crítico com os trabalhos produzidos na Faculdade de Filosofia, Ciências e Letras da USP, sobretudo (embora não exclusivamente) os da Cadeira de Sociologia I, não é possível aquilatar devidamente os sentidos e os alcances de suas formulações.

Nesse sentido, a ideia aqui será reconstituir analiticamente o modo pelo qual o crítico se apropria - de modo seletivo e muito próprio - do debate que estava em curso na Cadeira de Sociologia I da USP na passagem dos anos I950 para a década seguinte. A Cadeira, comandada por Florestan Fernandes, que primeiro a assumiu como regente (entre I954-I964) e depois como titular (de I964 até a aposentadoria compulsória em I969), contava ainda, entre seus assistentes, com Fernando Henrique Cardoso, Octavio Ianni, Maria Sylvia de Carvalho Franco, Marialice Mencarini Foracchi e Luiz Pereira. Nosso intuito é mostrar como Schwarz se ligou

3 Vale a pena assinalar de passagem, como mostra Lidiane Rodrigues (20II), que a aproximação de Roberto Schwarz em relação a Antonio Candido se deu, em seu princípio, de forma indireta, através de Anatol Rosenfeld, seu tutor, que em I956 passa a colaborar na seção Letras Alemãs do Suplemento Literário do jornal O Estado de S. Paulo. De acordo com Rodrigues, o próprio texto “Sobre O amanuense Belmiro”, publicado originalmente no suplemento literário do Última Hora, pode ser entendido como uma das tentativas de Schwarz de se aproximar daquele que seria seu mestre, de chamar a sua atenção, uma vez que Antonio Candido já havia se debruçado, anos antes, sobre o romance de Cyro dos Anjos. Após Candido ler o seu texto, como nota o próprio Schwarz em entrevista, convida-o para colaborar no Suplemento Literário d’O Estado de São Paulo (cf. SCHWARZ, 2009). 
aos trabalhos produzidos na Cadeira de Sociologia I, mais especificamente aos trabalhos de Fernandes, Cardoso e Franco da primeira metade da década de I96o. Em outras palavras, o nosso objetivo é, em um primeiro momento, assinalar como Schwarz apreende a crítica de Franco, em Homens livres na ordem escravocrata (I969), ao diagnóstico de Cardoso, em Capitalismo e escravidão no Brasil meridional (I962), que entendia a sociedade brasileira como patrimonial. Ao invés de concedermos ênfase, portanto, no plano de suas referências sociológicas, às proximidades entre Schwarz e Cardoso, empreendimento realizado com sistematicidade por Brito (20I9) na chave de uma "nacionalização do marxismo" - proximidades devidamente registradas pelo próprio Schwarz em diversas ocasiões -, sustentaremos que o crítico incorpora de modo decisivo, para a apreensão do princípio formal da "volubilidade" de Memórias póstumas de Brás Cubas (I88I), de Machado de Assis, boa parte da crítica de Franco ao diagnóstico de Cardoso a respeito da categoria "patrimonialismo”. Em um segundo momento, procuraremos registrar como a noção de "dilema social" elaborada por Fernandes no começo dos anos I960 já colocava, em seus próprios termos, a questão da "desfaçatez de classe", depois desenvolvida nos estudos de Schwarz sobre Machado.

Vale assinalar que Lidiane Rodrigues (20II), em trabalho de fôlego sobre os integrantes do Seminário sobre $O$ capital, também se voltou para as relações de Schwarz com os trabalhos de Cardoso e Franco, mostrando como o crítico literário procurou conectá-los de modo a dar conta do nexo entre liberalismo e capitalismo no Brasil oitocentista. De acordo com a autora, Schwarz relacionaria as perspectivas de Franco e Cardoso ao empreender um movimento de abstração do referente empírico de ambos, histórico e geográfico; além disso, ela também destaca como esse mesmo movimento liga Schwarz às teses de Fernandes, mesmo que de modo enviesado e a despeito da rarefação de referências explícitas aos livros do catedrático da Sociologia I (cf. RODRIGUES, 2OII, p. 466). Se, de um lado, Rodrigues se debruça sobre as relações de Schwarz com os trabalhos de Franco e Cardoso de modo a pensar os princípios de composição do tipo de leitura do Brasil efetuada pelo crítico, nosso objetivo passa por uma discussão mais específica a respeito da controvérsia em torno da categoria "patrimonialismo". Como procuraremos demonstrar, a divergência entre Franco e Cardoso em relação ao uso da categoria weberiana "patrimonialismo" pode ter cumprido um importante papel para a detecção do princípio formal da "volubilidade", analisado por Schwarz em Um mestre na periferia do capitalismo: Machado de Assis (I990). Já a aproximação efetuada entre Schwarz e Fernandes passará pela relação que destacaremos entre a "volubilidade" (e sua consequente "desfaçatez de classe”), enquanto modo de orientação da conduta das elites senhoriais brasileiras oitocentistas, e a categoria "dilema social”, desenvolvida pelo último também em notação weberiana. Ou seja, se de um lado, Schwarz extrai consequências cognitivas das críticas de Franco ao uso por ela considerado a-histórico da categoria "patrimonialismo" por parte de Cardoso para a análise da "volubilidade" senhorial, por outro, tal noção guarda um inesperado ar de família com a categoria "dilema”, construída anos antes por Fernandes.

Essa localização da reflexão de Schwarz diante dos trabalhos da Cadeira de Sociologia I também se afigura instigante ao olharmos de perto a sua relação com Florestan Fernandes. Se, por um lado, no âmbito da Cadeira de Sociologia I, Cardoso 
e Franco são referências intelectuais assumidas pelo crítico literário (SCHWARZ, 2008b), por outro lado, em relação a Fernandes, Schwarz sempre procurou tomar certa distância. Ao ser indagado em entrevista se havia sido aluno de Florestan, afirma: "Não fui. Mas vou confessar um pecado. Eu implicava com a linguagem dele” (SCHWARZ, 2009, p. 229). Além disso, ao procurar Antonio Candido para conversar a respeito de sua insatisfação com a escolha pelo curso de graduação em ciências sociais, não deixaria de ressaltar o seu abatimento com o caráter empírico da investigação sociológica: "os levantamentos e as tabulações não eram comigo" (SCHWARZ, 20I2b, p. 284). Entretanto, esse afastamento não seria exclusividade sua, posto que os integrantes do "Seminário d'O capital", do qual Schwarz fez parte, não convidaram Fernandes para participar, o que não anularia, ainda que na sua ausência, a onipresença flagrante do mestre (RODRIGUES, 20II). Contudo, apesar da distância sustentada por Schwarz, o argumento mais geral da Cadeira de Sociologia I da USP e do "Seminário d'O capital" marca decisivamente os seus trabalhos, ao incorporar, nos termos de Elide Rugai Bastos (2002), a recusa de Fernandes e seus discípulos no que diz respeito a uma visão dualista 4 .

Este trabalho se beneficia enormemente da fortuna crítica mais recente de Roberto Schwarz, que vem procurando aprofundar, de modo renovado, a reflexão sobre a sua obra e perspectiva. Seja indicando, por exemplo, as suas silenciosas divergências com Antonio Candido a respeito da sociedade brasileira (cf. MELO, 20I4), seja chamando a atenção para as suas relações com a teoria crítica de Frankfurt, em particular com Theodor Adorno - referencial decisivo para a construção de sua interpretação do Brasil -, bem como sua inserção nas discussões travadas no âmbito do "Seminário sobre $O$ capital", na USP (cf. QUERIDO, 20I9). Podemos apontar ainda o ensejo em qualificar o sentido assumido pela modernização na interpretação do país construída por Schwarz, discussão que vem ganhando corpo (cf. BUENO, 2008; QUERIDO, 20I3; CEVASCO, 20I4), bem como a sistematização dos debates em torno de sua obra realizada por sua fortuna crítica (cf. CEVASCO; OHATA, 2007; MOURA, 2OII; RICUPERO, 20I3).

Nossa contribuição específica para esse debate pretende sugerir que, ao se debruçar sobre a volubilidade de um cavalheiro da sociedade de corte fluminense - volubilidade essa que não pode ser entendida como uma idiossincrasia da personagem narradora do romance, posto que nela se encontraria implicada uma "problemática nacional” (SCHWARZ, 200ob, p. 47) -, Schwarz igualmente estava se posicionando em relação às diferentes formulações sobre a sociedade brasileira presentes na Cadeira de Sociologia I. Para isso, localizaremos o argumento de Um

4 É claro que o destaque que estamos aqui conferindo aos trabalhos da Cadeira de Sociologia I não implica dizer que Schwarz foi indiferente ao contexto mais amplo das ciências sociais brasileiras. Basta lembrar, por exemplo, que, desde outra matriz de aclimatação das teses de Weber sobre o "patrimonialismo" para o Brasil, Raymundo Faoro realizava simultaneamente a Schwarz uma penetrante análise sobre a obra machadiana, que seria capaz de iluminar como poucas o mundo social do Segundo Reinado, em Machado de Assis:a pirâmide e o trapézio (I974). O aprofundamento da ressonância de certas teses de Weber nos textos de Schwarz torna necessário o cotejamento com a obra de Faoro. Para uma análise comparativa entre Schwarz e Faoro - partindo, porém, de outras questões - cf. Waizbort, 2007. 
mestre na periferia do capitalismo em relação às pesquisas de Fernandes, Cardoso e Franco, especialmente no que se refere, respectivamente, aos livros A integração do negro na sociedade de classes (FERNANDES, I965), Capitalismo e escravidão no Brasil meridional (CARDOSO, I997) e Homens livres na ordem escravocrata (FRANCO, I997). Nosso texto está divido em três partes, além desta introdução. Na primeira, reconstituiremos sinteticamente os argumentos de Schwarz sobre a "volubilidade narrativa” de Memórias póstumas de Brás Cubas. Na segunda, mostraremos como a crítica de Maria Sylvia de Carvalho Franco ao uso do conceito de "patrimonialismo" por Fernando Henrique Cardoso parece ter jogado papel crucial para a construção da categoria "volubilidade", com consequências decisivas para a interpretação da sociedade brasileira contida no exercício crítico de Schwarz. Por fim, ainda que brevemente, acentuaremos o contraste entre as formulações de Schwarz e de Fernandes sobre as camadas burguesas no Brasil e suas relações com os valores civilizatórios modernos, uma vez que, cada um a seu modo - em diferentes níveis e registros - refletiu sobre a típica "desfaçatez de classe" que informa historicamente as condutas desses atores sociais no país.

\section{DESCONTINUIDADE E VOLUBILIDADE: MOTO-PERPÉTUO}

Tomando como ponto de partida a análise de Roberto Schwarz sobre os primeiros romances de Machado de Assis, em Ao vencedor as batatas, podemos perceber como o intérprete parece identificar certo processo de acumulação estética em curso, que flagra o modo pelo qual a perspectiva crítica do escritor, paulatinamente, ganharia em densidade. Schwarz salienta que, malgrado os primeiros romances de Machado de Assis cortarem as conexões do Brasil patriarcal e escravocrata com o mundo, uma vez que o ideário liberal-burguês é colocado em segundo plano, a filiação conservadora e antiliberal do escritor, plasmada nesses romances, teria permitido que a matéria social local emergisse ao primeiro plano da composição. Ou seja, na leitura proposta por Schwarz, a literatura brasileira teria se beneficiado, em grande medida, do caráter antiliberal dos primeiros romances machadianos, principalmente no que se refere à construção de uma representação literária mais verossímil da sociedade brasileira do século XIX.

Ao identificar a família como o eixo de organização desses romances, Schwarz focaliza os ganhos substantivos permitidos pelo procedimento de codificação de uma dimensão fundante da experiência social brasileira, referente à dinâmica da prestação e contraprestação de favores. Retomando o fio da análise de Maria Sylvia de Carvalho Franco, em Homens livres na ordem escravocrata, o crítico assinala, em "As ideias fora do lugar", capítulo de abertura do livro Ao vencedor as batatas ${ }^{5}$, que a sociedade brasileira oitocentista poderia ser dividida entre três grupos sociais distintos: o dos proprietários rurais e o dos escravos, cujos vínculos socioeconômicos ligados à produção orientada para o abastecimento do

5 O artigo "As ideias fora do lugar" aparece pela primeira vez na revista Estudos do Centro Brasileiro de Análise e Planejamento (Cebrap), em I973. 
mercado externo tornaria os homens livres pobres economicamente inorgânicos. A sobrevivência desse grupo social destituído de propriedades e excluído da relação produtiva fundamental estaria cronicamente dependente do favor dos grandes proprietários rurais, algo que seria trazido à tona por Machado de Assis, em pleno milieu urbano, em seus primeiros romances ${ }^{6}$.

E não seria exagero inferir que o diagnóstico do crítico sobre os primeiros romances machadianos acabaria por aproximar o tipo de narrativa ficcional do escritor do Rio de Janeiro às formulações de Gilberto Freyre, pois a tese do patriarcalismo enfatiza justamente o papel assumido pela família patriarcal brasileira na estruturação da sociedade, o que afastaria o risco de uma resolução disruptiva para os conflitos sociais (BASTOS, 2006)7. Vale a pena lembrar que, nas palavras de Schwarz, os primeiros romances de Machado de Assis não apresentariam qualquer "brisa de revolta social”, tornando "sensível a estreiteza do conflito central, em que rearranjos na esfera doméstica fazem figura de solução de conflitos sociais” (SCHWARZ, 2000a, p. 85-86).

Aqui, não custa abrir parêntesis, pois, como ressalta Rodrigo Ramassote (2006), em I95I, Antonio Candido publica, no livro Brazil: portrait of a half a continent, organizado por Lynn Smith e Alexander Marchant, artigo intitulado "The Brazilian family". Nele, a análise da família patriarcal brasileira constituiu uma das preocupações de Candido que, inclusive, estabeleceu diálogo direto com as formulações propostas por Freyre (cf. RAMASSOTE, 2006, p. I39). Não podemos esquecer, nesse sentido, que Schwarz cursou, em I958, quando se encontrava no terceiro ano da graduação em ciências sociais na USP, a disciplina “Organização Social Brasileira”, ministrada por Candido (RAMASSOTE, 2006, p. 46). Ou seja, tanto o artigo de Candido quanto o fato de que Schwarz tenha cursado a disciplina lecionada por seu mestre nos permitem sugerir que a relação entre o diagnóstico do discípulo a respeito da família nos primeiros romances de Machado não se encontra talvez muito distante de uma interlocução com a tese do patriarcalismo.

A perspectiva conservadora e antiliberal de Machado de Assis teria sido a razão

6 Na interpretação de Roberto Schwarz, o favor seria "o mecanismo através do qual se reproduz uma das grandes classes da sociedade [o crítico se refere aqui aos homens livres pobres], envolvendo também outra, a dos que têm [este seria o grupo social dos grandes proprietários]" (SCHWARZ, 2000a, p. I6). Radicalizando o ponto, Schwarz enfatiza que o favor seria "a nossa mediação quase universal" (SCHWARZ, 2000a, p. I6), atuando como o elemento que contribuiria decisivamente para reorientar e ressignificar o sentido das ideias, princípios, condutas e instituições liberais no Brasil, o que geraria inclusive impasses estético-formais, os quais seriam representativos no romance Senhora, de José de Alencar, por ele analisado em Ao vencedor as batatas. Na dissertação de mestrado de Karim Helayel (20I5), a interpretação do Brasil de Roberto Schwarz é reconstituída, sendo concedida ênfase à sua discussão sobre as relações de favor e tendo como ponto de chegada a sua localização diante das interpretações das sociólogas Maria Sylvia de Carvalho Franco e Maria Isaura Pereira de Queiroz.

7 Não podemos deixar de assinalar, obviamente, a noção de "antagonismos em equilíbrio", presente na obra de Gilberto Freyre, tão densamente estudada por sua fortuna crítica (cf. ARAÚJO, 2005; BASTOS, 2006) e que guarda proximidade com a dinâmica familiar identificada por Roberto Schwarz nos primeiros romances de Machado de Assis. 
para o profundo mergulho no complexo jogo da cooptação e das relações de favor, imersão essa que seria adensada em dois dos grandes romances de sua segunda fase, Memórias póstumas de Brás Cubas e Dom Casmurro (I899). Ao constituir a "origem do impulso analítico" (SCHWARZ, 2000a, p. 92) de seus primeiros romances, Schwarz enseja evidenciar que a família seria internalizada e codificada no plano da forma literária, o que permitiria uma entrada verossímil no modo pelo qual a conduta dos atores sociais é permanentemente interpelada pela lógica das relações sociais brasileiras. Para o crítico, o que vincularia os primeiros romances de Machado de Assis entre si seria "a afirmação enfática da conformidade social, moral e familiar, que orienta a reflexão sobre os destinos individuais" (SCHWARZ, 2000a, p.88). Ainda que não disponhamos de tempo para uma análise detalhada de sua interpretação sobre os primeiros romances de Machado de Assis, gostaríamos de destacar que eles são entendidos pelo crítico como o ponto de partida do processo de complexificação do olhar do escritor, desembocando em seus romances maduros, como é o caso de Memórias póstumas de Brás Cubas, analisado em Um mestre na periferia do capitalismo.

Passando a Memórias póstumas de Brás Cubas - romance no qual o escritor assume um ponto de vista plenamente desencantado por meio da adoção da perspectiva senhorial ${ }^{8}$-, Schwarz identifica uma oscilação discursiva por parte do narrador, a qual seria representativa do andamento particular da sociedade brasileira. $\mathrm{O}$ narrador comporia um discurso no qual a alternância constante de perspectivas constituiria o nervo estético, com modulações que codificariam os caprichos insaciáveis de um membro pertencente às elites senhoriais brasileiras. Mobilizando os termos propostos por Antonio Candido, Schwarz assinala que as Memórias operariam a "redução estrutural" do modo de orientação da conduta próprio às elites senhoriais brasileiras, que se encontrariam entre dois receituários contrastantes: 0 legado pelas instituições liberais burguesas, calcadas nos princípios da autonomia individual, da igualdade, do universalismo e do trabalho livre; e aquele proveniente da sociedade escravocrata brasileira, diante do qual tais princípios forjados na aurora da sociedade burguesa sairiam desautorizados.

Brás Cubas oscilaria constantemente, enquanto tipo social representativo das camadas dominantes, numa espécie de movimento pendular entre esses dois polos distintos de orientação das condutas, optando por um ou outro, a seu bel-prazer.

8 Ao concluir o seu Ao vencedor as batatas, Roberto Schwarz observa que Machado de Assis, tendo completado a sua ascensão social, acabaria por alterar concomitantemente a sua perspectiva, uma vez que o ponto de vista adotado em seus romances de maturidade - cuja crítica seria revestida por uma fina e ácida ironia - divergiria daquele assumido em A mão e a luva (1874), Helena (I876) e Iaiá Garcia (I878). Nesses romances, o escritor teria assumido a perspectiva daqueles sujeitos que se encontravam inscritos em uma situação de dependência pessoal em relação aos grandes proprietários, vivendo de seu favor. Tais romances exprimiriam a crença e o otimismo na possibilidade de reconhecimento social dos dependentes talentosos por parte dos senhores, que seriam aureolados por um "paternalismo esclarecido que aproveita os dons naturais e a iniciativa do beneficiado, em lugar de sacrificá-los" (SCHWARZ, 2000a, p. 99).

9 O método de "redução estrutural" é qualificado por Antonio Candido (20Io, p. 9) como "o processo por cujo intermédio a realidade do mundo e do ser se torna, na narrativa ficcional, componente de uma estrutura literária, permitindo que esta seja estudada em si mesma, como algo autônomo”. 
Assim, a volubilidade que informaria o caráter do narrador das Memórias não seria uma especificidade sua, mas particularidade dos grupos dominantes e privilegiados da sociedade brasileira como um todo. Acompanhando passo a passo, portanto, o caráter ambíguo do narrador, o crítico identifica na sua volubilidade o princípio formal do romance, ou seja, a codificação do modo de proceder das elites senhoriais brasileiras. A volubilidade não seria entendida, desse modo, apenas como recurso literário, uma vez que a oscilação do narrador o denunciaria como "parte facciosa da história" (SCHWARZ, 200ob, p. I72). Portanto, ao ter em vista a feição volúvel do narrador, Schwarz afirma tratar-se "da universalização dos esquemas de conduta da classe dominante brasileira, ou seja, da construção de seus efeitos - calamitosos - sobre as grandes linhas da civilização contemporânea, para além do contexto empírico imediato" (SCHWARZ, 200ob, p. I74).

\section{As Raízes da VolubiLIDAde}

Não podemos deixar de notar que o diagnóstico mais sistemático da volubilidade começa a ser formulado pelo crítico em Ao vencedor as batatas, uma vez que a descontinuidade na conduta senhorial já seria identificada como um princípio constitutivo na narrativa ficcional dos primeiros romances de Machado de Assis. Vale a pena recuperar Ao vencedor as batatas para mostrar como a problemática da volubilidade é formulada por Roberto Schwarz, que, ao conferir ênfase ao caráter volúvel das elites senhoriais brasileiras, acaba por se aproximar da visão de Maria Sylvia de Carvalho Franco, que não entendia a sociedade brasileira como patrimonial.

Um bom exemplo da descontinuidade das elites senhoriais na análise procedida em Ao vencedor as batatas é o jogo de compensações promovido pela matriarca Valéria, personagem do romance Iaiá Garcia (I878), jogo esse que levaria em consideração a boa vontade de seus dependentes em relação a ela. Ainda que Schwarz saliente que o arbítrio das elites senhoriais seja informado por um moto descontínuo, não deixa de assinalar que os dependentes seriam percebidos pelas camadas dominantes como merecedores de compensações materiais ou simbólicas, o que levaria a dimensão das descontinuidades para o segundo plano. Conforme lembra o crítico, ao propor "a Estela, um homem por outro homem; a Luís Garcia, uma esposa por um constrangimento; a Jorge, a glória militar por Estela” (SCHWARZ, 2000a, p. I93), o que se encontraria em jogo seria a imposição dos ensejos de Valéria, cuja mediação seria papel das compensações concedidas a seus dependentes. Apesar de frustrar os desejos de seus dependentes, Schwarz ressalta que a matriarca não descuraria do momento da reparação, a partir do qual preservaria o bom ânimo de seu séquito. Assim, a questão que segue é fundamental para o entendimento da prestação e contraprestação de favores em Iaiá Garcia: "se a satisfação do dependente é negligenciável quando não vai com a outra, ela é também indispensável, pois o que vale um protetor cujos dependentes vivam insatisfeitos?” (SCHWARZ, 2000a, p. I94).

Malgrado identificar a preocupação senhorial em manter a boa vontade de seus dependentes, Schwarz constata que sua satisfação somente seria permitida desde que houvesse a anuência das elites, debate esse que assume tonalidade distinta através 
do diagnóstico da volubilidade de Brás Cubas. Em Iaiá Garcia, "a descontinuidade não é privilégio dos dependentes. Embora diversamente, ela se encontra também do lado dos senhores - ela é da definição do arbitrário" (SCHWARZ, 2000a, p. I96). A descontinuidade operaria, na interpretação proposta pelo crítico, como elemento-chave em Iaiá Garcia, permitindo entrever as inconstâncias da parte dominante, algo que seria plenamente assumido e exponenciado na construção do narrador machadiano da segunda fase.

Ao tratar da descontinuidade como fundamento do caráter arbitrário das elites senhoriais brasileiras oitocentistas, podemos identificar aqui a ressonância da crítica de Maria Sylvia de Carvalho Franco a Fernando Henrique Cardoso em relação à mobilização por ela considerada improcedente da categoria "patrimonialismo". Como assinalamos anteriormente, tanto Franco quanto Cardoso são duas referências intelectuais consideradas cruciais por Schwarz, conforme ele mesmo afirma em entrevista concedida a André Botelho e Lilia Schwarcz (2008). Nas palavras do crítico literário:

Havia, de um lado, Fernando Henrique Cardoso, com Capitalismo e escravidão no Brasil meridional, que procurava mostrar que a escravidão - o desvio - não era o contrário do capitalismo - a norma internacional -, ao qual até certo momento ela foi útil. Portanto, a oposição entre capitalismo e escravidão não era o que parecia. Atrás da fachada liberal havia um mundo mental quase clandestino, sobretudo do ângulo europeu oficial. Ruminei bastante a tese de Fernando Henrique, mas faltava algo para chegar em Machado. Aí apareceu o livro de Maria Sylvia de Carvalho Franco. (SCHWARZ, 2008b, p. I49).

Entretanto, a contrapelo do destaque conferido por Schwarz à complementariedade entre os trabalhos de Franco e Cardoso, gostaríamos de sublinhar aqui as suas divergências, principalmente no que diz respeito à utilização da categoria "patrimonialismo". Talvez não seja descabido avançar o argumento de que é através da controvérsia explicitada pela crítica de Franco (I997), em Homens livres na ordem escravocrata, ao modo pelo qual Cardoso (I997) mobiliza, em Capitalismo e escravidão no Brasil meridional, a categoria "patrimonialismo", que podemos identificar as raízes da interpretação de Schwarz acerca da volubilidade das elites senhoriais brasileiras. Em outras palavras, a crítica de Franco a Cardoso, a qual marca uma flagrante descontinuidade entre as suas interpretações do Brasil, parece ser mais fecunda do que as suas possíveis convergências para pensarmos o diagnóstico da volubilidade.

Recapitulando, Cardoso qualifica, em Capitalismo e escravidão no Brasil meridional, o tipo de dominação que teria se desenvolvido no Rio Grande do Sul como patrimonial. Devido aos imperativos decorrentes do processo de ocupação, povoamento e defesa territorial em uma região convulsionada por intensos conflitos, no Rio Grande do Sul teria se desenvolvido uma "estrutura patrimonialista", haja vista que a subordinação pessoal ao "senhor" constituiria o pressuposto decisivo para a concessão de prebendas. Sua análise ressalta que a sociedade gaúcha teria se configurado como uma "estrutura patrimonialista", 
perpassada pelas especificidades do processo de formação da região, cujas marcas seriam o "arbítrio" e a "violência", permitindo-lhe a inferência de que o "sistema patrimonialista de poder" teria sofrido uma "distorção no sentido de um tipo de poder sultanístico, embora jamais a estrutura global de dominação se tivesse configurado conforme esse poder tradicional” (CARDOSO, I997, p. III). Segundo Cardoso, apesar de constituir uma falácia caracterizar a sociedade rio-grandense por meio da noção de "sultanato" - levando em conta que "as normas formais imperantes e mesmo os limites impostos pela hierarquia de poder formalmente estabelecida não permitiriam tal caracterização" (CARDOSO, p. I03) -, no período em que se desenhou a configuração da "sociedade patrimonialista", a passagem do domínio absoluto e praticamente irrestrito do chefe local para aquele que se faria em "nome da lei e de 'El-rei, nosso Senhor" ter-se-ia desenvolvido por meio do "arbítrio pessoal" e da "insolência" dos detentores dos "cargos de mando". As posições burocráticas apropriadas estamentalmente pelos mandatários locais tornaram possível o uso do poder estatal para o incremento de seu prestígio pessoal e para o robustecimento de seu poderio econômico. Assim, Cardoso pondera que o sentido da "ordem patrimonial-estatal" teria sido subvertido, assentando as bases que permitiriam o desenvolvimento, no Rio Grande do Sul, de uma sociedade escravocrata e latifundiária, cuja conformação se aproximaria mais do "patrimonialismo patriarcal".

Divergindo frontalmente do diagnóstico patrimonialista de Cardoso, em Homens livres na ordem escravocrata, Franco (I997) nega procedência à mobilização da categoria "tradicional" para a análise da sociedade brasileira, o que inviabilizaria a utilização do conceito de "patrimonialismo" tal como efetuado por seu colega ${ }^{\text {To }}$. A socióloga paulista afirma que a interdependência existente entre os grandes proprietários rurais e seus dependentes teria logrado vigência apenas no âmbito da política, o que tornaria improcedente a qualificação da sociedade brasileira como patrimonial. Os dependentes constituiriam uma ampla parcela de seu eleitorado, o que teria gerado obrigações, por parte dos proprietários, no intuito de garantir a subserviência daqueles homens livres pobres que compunham o seu séquito. Assim, na interpretação de Franco não teria se sucedido entre os homens livres do Brasil oitocentista uma relação com base em pressupostos que tornariam possível a sua designação como patrimonial, uma vez que os limites impostos pela "tradição", que poderiam demarcar a esfera de atuação do arbítrio senhorial, seriam extremamente fluidos. Em decorrência dos imperativos econômicos de expansão de seus negócios, em momento algum os latifundiários teriam vacilado em expulsar os seus sitiantes e agregados de suas terras, rompendo a trama da prestação e contraprestação de favores, à qual o seu poder se encontrava atrelado. Nos termos de Franco:

Io A controvérsia entre Maria Sylvia de Carvalho Franco e Fernando Henrique Cardoso foi discutida em detalhe por trabalhos que se debruçaram sobre a obra da socióloga paulista, os quais desempenharam importante papel para que a reconstituíssemos. Para mais detalhes a respeito da crítica de Franco a Cardoso, cf.: Hoelz, 20I0; Botelho, 20I3; Cazes, 20I3. A respeito dos desdobramentos posteriores da crítica de Franco a Cardoso, tendo em vista o modo particular pelo qual este se posicionou, cf. Helayel, 2018. 
Nos estritos quadros da vida econômica nada restringia sua arbitrariedade: explorou o trabalho escravo, e a eventual privação de outras fontes de mão de obra em nada afetava seus interesses centrais. Daí resulta que entre homens livres não chegou a se constituir uma relação patrimonial típica. Nesta, o amplo e exclusivo aproveitamento da força de trabalho do dependente, que é insubstituível, torna inelutável preservar sua disposição e capacidade de bem servir, o que gera uma certa sujeição para o senhor, definindo obrigações de sua parte. No Brasil, é apenas ao se penetrar na vida política que se observa uma reciprocidade desse tipo: nela, os serviços do "cliente" eram vitais para os grupos dominantes e se conjugaram aos deveres que estes assumiram e cumpriram. Nesse caso, em que estavam em jogo objetivos básicos como apoio político versus auxílio econômico, consolidava-se a interdependência. (FRANCO, I997, p. 90-9I).

A socióloga ressalta, nesse sentido, que os proprietários rurais teriam sido interpelados por duas lógicas contrastantes de coordenação das relações sociais: pela do mercado - cujos interesses seriam orientados por uma perspectiva ordenada com base em princípios racionais e impessoais - e pela da dominação pessoal - à qual se encontrariam vinculadas as práticas decorrentes das relações de favor. Dessa maneira, o fio que ataria os senhores rurais aos seus dependentes seria rompido a despeito dos últimos. Tendo em vista a tensão constitutiva entre "associações morais" e "constelações de interesses", Franco assinala que as práticas capitalistas abalariam as frágeis instituições assentadas sobre as "associações morais". As promessas realizadas com base nas relações pessoais estabelecidas entre fazendeiros e dependentes seriam frustradas pelos primeiros, que estariam presos à lógica racionalizada do mercado, avessa à manutenção de preceitos "tradicionais". Ou seja, não obstante o sistema autoritário de dominação entre homens livres ter sido erigido com base em "associações morais”, os grupos dominantes teriam norteado a sua conduta, sobretudo, através de "constelações de interesses”, rompendo, sempre que julgassem necessário, os compromissos contraídos com seus dependentes. Desse modo, para a autora, o alicerçamento de laços tradicionais nas relações entre homens livres no Brasil oitocentista seria inviabilizado, já que a sua dinâmica teria sido marcada por seu caráter extremamente contingente, caráter esse proveniente do sentido capitalista que orientaria a produção, tolhendo a existência efetiva de uma ordem patrimonialista.

Levando em consideração a tensão entre "associações morais" e "constelações de interesses”, que cumpre papel decisivo na formulação da crítica de Franco a Cardoso, podemos dizer que nela parece residir a chave para entendermos a ênfase de Schwarz na descontinuidade que informaria a narrativa ficcional de Iaiá Garcia e que seria aprofundada com a interpretação sobre a volubilidade das elites senhoriais. No entanto, na análise do livro Iaiá Garcia, apesar de ressaltar o arbítrio de Valéria, o crítico enfatiza o caráter interdependente entre a matriarca e seus agregados/ dependentes, dimensão que teria o seu sentido subvertido em Memórias póstumas de Brás Cubas, no qual o poder discricionário e os caprichos de um membro pertencente à elite senhorial brasileira anulariam qualquer preocupação em preservar a boa disposição de seus asseclas.

Visto por esse ângulo, podemos dizer que o crítico literário se aproxima da crítica 
de Franco em relação à perspectiva de Cardoso para a construção do diagnóstico da "volubilidade". A crítica de Franco ao modo pelo qual Cardoso faz uso do conceito de "patrimonialismo" parece operar de modo decisivo na proposta interpretativa de Schwarz a respeito da volubilidade das elites senhoriais brasileiras. Sistematizando o ponto: se, em Ao vencedor as batatas, Schwarz parece se aproximar do diagnóstico patrimonialista, no sentido atribuído por Max Weber ${ }^{\text {II }}$ à categoria - a despeito de não o citar diretamente -, por outro lado, em Um mestre na periferia do capitalismo, a interdependência pressuposta pelo conceito sairia desautorizada pela volubilidade e desfaçatez de Brás Cubas. Assim, ao identificar a volubilidade como princípio formal das Memórias, Schwarz parece concordar com a crítica de Franco a respeito da inviabilidade do diagnóstico patrimonialista para a qualificação da sociedade brasileira do século XIX.

Como sugere o crítico, dado o acento expansionista sem fronteiras dos caprichos do narrador das Memórias, a volubilidade traria à tona, apesar de constantemente infringir a norma burguesa, certa "inquietação fáustica" aclimatada ao contexto brasileiro. Seguindo o argumento de Schwarz, tal redefinição da "inquietação fáustica" pela matéria local, acabaria por exonerar "a classe dominante da obrigação para com os dominados, dando-lhe latitude total à irresponsabilidade" (SCHWARZ, 200ob, p. 64). Ou seja, se nos primeiros romances de Machado de Assis vigoraria a preocupação dos proprietários com a promoção dos dependentes sobretudo os mais talentosos romances nos quais "lealdade e compromisso" deveriam preponderar sobre a "definição burguesa do interesse, à qual no entanto os proprietários não podiam também deixar de estar submetidos" (SCHWARZ, 200ob, p. 232) -, nas Memórias póstumas de Brás Cubas, a volubilidade do narrador anularia quaisquer compromissos porventura adquiridos para com os mais pobres. Se lembrarmos aqui da leitura proposta por Milton Ohata (2007) do trabalho de Antonio Candido, intitulado Um funcionário da monarquia, verificaremos que a "ascensão à brasileira" de Antonio Nicolau Tolentino teria dependido, em boa parte, dos favores de seus padrinhos na burocracia, guardando, nesse sentido, afinidades com as perspectivas de Helena e Iaiá Garcia nos primeiros romances de Machado de Assis, personagens esperançosas em relação às remotas possibilidades de civilizar as práticas das relações de favor. Mas, como lembra o autor, em sua empreitada, Tolentino não deixaria de ter que lidar com a crueza do "caráter antissocial da classe dominante brasileira”, sendo, em dado momento, derrotado pelo patronato (cf. OHATA, 2007, p. 292-293).

Se colhermos alguns exemplos utilizados por Roberto Schwarz (2000b) em seu Um mestre na periferia do capitalismo, mobilizados para pensar o desvalimento e o

II De acordo com Max Weber, a manutenção da boa vontade dos súditos, por parte do governante patrimonial, aparece decisivamente na formulação da categoria "patrimonialismo". Weber destaca a "exigência de reciprocidade", por parte dos submetidos, uma vez que o senhor dependeria, em grande medida, no caso do aproveitamento descentralizado dos membros pertencentes à comunidade doméstica, de sua "boa vontade no cumprimento dos deveres e sempre da conservação de sua capacidade de prestar-lhe serviços. Também o senhor 'deve', portanto, alguma coisa ao submetido, não juridicamente, mas de acordo com o costume” (WEBER, I999, t. 2, p. 237). Para uma análise sobre o modo pelo qual Maria Sylvia de Carvalho Franco se vale da categoria weberiana "patrimonialismo" em seus trabalhos para formular sua crítica a Cardoso, cf. Cazes, 20I3. 
trágico destino dos dependentes, poderemos lembrar de Eugênia, que, além da opção de poder conseguir um bom casamento, posto que educada na proximidade com o mundo senhorial, "pode também terminar, como termina, pedindo esmola num cortiço” (SCHWARZ, 200ob, p. 87). Há também o caso de Dona Plácida, cuja vida de "trabalho humilde e honrado" não colheria nenhum reconhecimento. Dona Plácida seria representativa da condição do pobre na sociedade brasileira, ao internalizar tanto o desvalimento quanto a sua falta de garantias, uma vez que "a vida honesta e independente não está ao alcance do pobre, que aos olhos dos abastados é presunçoso quando a procura, e desprezível quando desiste, uma fórmula, aliás, do abjeto humor de classe praticado por Brás e exposto por Machado de Assis” (SCHWARZ, 200ob, p. I07). Portanto, levando em conta a volubilidade das elites senhoriais brasileiras, os proprietários se desobrigariam em relação ao destino dos pobres, imprimindo-lhes um futuro em que a "falta de garantia" (SCHWARZ, 2000b, p.I05) configuraria a tônica.

Para efetuar a denúncia do poder discricionário dos grandes proprietários, Machado de Assis teria operado uma mudança significativa de registro, investindo-se do figurino e do discurso dominantes ao adotar um narrador em primeira pessoa. Seria por meio dele, afirma Schwarz, que seriam desvelados os requisitos e o modus operandi da "volubilidade" e da "desfaçatez" das elites senhoriais ${ }^{12}$. Ao proceder a uma "leitura a contrapelo" ${ }^{\text {I3 }}$, o crítico procura desvelar o avesso do discurso hegemônico de Brás Cubas, movimento que lhe permitiria acessar a dinâmica das relações sociais do Brasil oitocentista, que não se confinariam ao século XIX, ainda reverberando na contemporaneidade. Ao ler a contrapelo a fina e oblíqua narrativa confeccionada por Brás Cubas, o crítico identifica que as elites senhoriais se valeriam tanto do que havia de mais moderno no receituário liberal-burguês, quanto de práticas ligadas ao paternalismo e à escravidão no Brasil. Como bem assinala Paulo Arantes (I992, p. 6I), "Roberto verá nas manhas narrativas do romancista uma Forma [...] a um tempo

I2 Se lembrarmos de sua interpretação a respeito de Dom Casmurro, veremos que Roberto Schwarz sublinha a importância de uma leitura a contrapelo do discurso do narrador, tendo em vista que Machado de Assis teria construído "situações narrativas" ou "narradores postos em situação", cujo caráter parcial e interessado constituiria o eixo da forma literária do livro, o "narrador unilateral" (SCHWARZ, I997). Ou seja, "Machado tomara o partido malicioso de fingir, na sincera primeira pessoa do singular, um figurão marcadamente retrógrado" (SCHWARZ, I997, p. 95). Contudo, faz-se necessário pontuar que o adjetivo "sincera” aparece em chave irônica, pois a marca dos "narradores postos em situação", forjados por Machado de Assis, seria, nos termos do crítico, a sua “desfaçatez de classe” (SCHWARZ, 20oob). Ou seja: "Camuflada pela primeira pessoa do singular, que a ninguém ocorreria usar em prejuízo próprio e com propósito infamante, a imitação ferina dos comportamentos da elite criava um quadro de alta mistificação: cabe ao leitor descobrir que não está diante de um exemplo de autoexame e requintada franqueza, mas de uma denúncia devastadora” (SCHWARZ, 2000b, p. I90).

I3 Para qualificarmos, brevemente, o procedimento de "leitura a contrapelo", podemos lembrar que, em "Sobre o conceito de História” (I940), Walter Benjamin (I994, p. 225) sublinha que o imperativo analítico de "escovar a história a contrapelo" seria tarefa do crítico materialista histórico. Tal imperativo enfatiza a necessidade de encaminhar o olhar na contramão da narrativa hegemônica disseminada pelos vencedores, a fim de problematizar e contrabater a versão oficial e dominante contada sobre os desdobramentos do processo histórico. Para uma análise pormenorizada sobre as teses de Benjamin, cf. Löwy, 2005. 
princípio de construção do livro e estilização de dinamismos sociais". A asserção de Arantes permite captar como a volubilidade seria transposta estilisticamente para o plano formal, cuja narrativa seria atravessada pela dinâmica da vida social. Assim, o filósofo sintetiza a questão, explicitando que, a partir do momento no qual os potentados da sociedade brasileira oitocentista considerassem o alinhamento com o léxico da "igualdade civil", passariam ao campo da "modernidade europeia" aclimatada ao país. Por outro lado, caso fosse de sua vontade e necessidade o estreitamento dos vínculos com os "laços morais do favor", as prerrogativas do "país colonial" tomariam a dianteira.

Roberto Schwarz ressalta, nessa direção, que a conexão do país ao sistema capitalista e aos princípios do liberalismo não alteraria "os modos atrasados de produzir", pelo contrário, colaboraria para a sua reprodução e promoção, "fundando neles uma evolução com pressupostos modernos, o que naturalmente mostrava o progresso por um flanco inesperado" (SCHWARZ, 200ob, p. 37). O procedimento volúvel mobilizado pelo narrador das Memórias seria convertido em técnica narrativa também volúvel, mostrando como a forma literária teria mimetizado a dinâmica e a experiência social brasileiras, por meio de sua reordenação e codificação (WAIZBORT, 2009).

Podemos dizer que a análise de Roberto Schwarz destaca uma persistente dialética sem síntese entre a norma burguesa e seu constante desrespeito, interesse discricionário e ideologia igualitária, sintetizada pelo crítico na prosa volúvel e caprichosa de Brás Cubas. O discurso confeccionado pelo narrador estaria associado à dinâmica conservadora da modernização, que se processaria repondo elementos do Brasil patriarcal e escravocrata. O processo de modernização se valeria, desse modo, do "atraso" presente em nossas relações sociais para se reproduzir, uma vez que o "arcaísmo" não seria de forma alguma excluído; pelo contrário, sua potência regressiva seria intensificada pelas formas modernas de vida.

A acomodação entre receituários distintos assumiria sentido dinâmico nas relações sociais locais, ressignificando o liberalismo e suas instituições, que passariam a operar no campo gravitacional de uma ordem social cujas coordenadas seriam designadas pela lógica pessoalizada das relações de favor. Contudo, não podemos deixar de assinalar que o movimento de acomodação entre princípios distintos de orientação das condutas comporta, na interpretação de Schwarz, um processo de aclimatação que não dirimiria as tensões causadas pelas torções sofridas por ideários, instituições e práticas estrangeiras. Acomodações e tensões ${ }^{\mathrm{I}}$, portanto, formalizadas também pela leitura de Schwarz (2008a) em relação aos primeiros anos

I4 Divergindo da crítica de Alfredo Bosi ao autor de Um mestre na periferia do capitalismo, Bernardo Ricupero (20I3) detecta certa oscilação na explicação de Schwarz no que se refere ao difícil processo de aclimatação das ideias e instituições liberais importadas pelo Brasil do século XIX. Ricupero chama a atenção para as "acomodações” e as “contradições” na maneira pela qual os argumentos de Schwarz se encontrariam estruturados. Para Ricupero, ao se voltar para as tensões brasileiras, o crítico oscilaria na explicação, ora preconizando a componente da acomodação, ora se voltando para os aspectos relativos às contradições presentes na sociedade e história brasileiras. 
da ditadura civil-militar brasileira, como podemos constatar em seu artigo "Cultura e política, I964-I969" (I970) ${ }^{\text {I5 }}$.

Nele, o intérprete assinala que o tipo de integração promovida pelo imperialismo contribuiria, haja vista os seus interesses imediatos, para a modernização da economia brasileira, revivendo e amplificando parte do "arcaísmo ideológico e político" de que precisaria para a manutenção de sua estabilidade (SCHWARZ, 2008a). De resíduo e mera excrescência, "o arcaísmo passa a instrumento intencional da opressão mais moderna, como aliás a modernização, de libertadora e nacional[,] passa a forma de submissão" (SCHWARZ, 2008a, p. 87). Na leitura de Schwarz, o contexto imediatamente anterior ao golpe civil-militar de I964 já operaria a articulação entre elementos arcaicos e modernos, afigurando-se representativa, nesse sentido, a "Marcha da família com Deus pela liberdade", que teria dinamizado os setores conservadores tanto do campo quanto da cidade, mobilizados contra o "divórcio", a "reforma agrária" e a "comunização do clero". Na crítica aguda do intérprete, "o golpe apresentou-se como uma gigantesca volta do que a modernização havia relegado; a revanche da província, dos pequenos proprietários, dos ratos de missa, das pudibundas, dos bacharéis em lei etc.", ressuscitando, desse modo, "o cortejo dos preteridos pelo capital” (SCHWARZ, 2008a, p. 83, 84). A despeito de tal constatação, observa que o ponteiro do relógio não teria andado para trás, uma vez que a ditadura civil-militar teria sido, sobretudo, moderna ao se encontrar alinhada e integrada, econômica e militarmente, aos Estados Unidos, promovendo a concentração e a racionalização da expansão do capital. O que estaria em jogo, portanto, assinala o intérprete, seria o caráter conservador e regressivo do tipo de modernização viabilizada pela ditadura civil-militar, que parece guardar íntima afinidade com a narrativa volúvel de Brás Cubas.

\section{DesfaÇATEZ de Classe: OUTRA VERSÃo?}

Vimos, portanto, que as formulações de Schwarz sobre a "volubilidade narrativa” e a "desfaçatez de classe" a ela associada são altamente devedoras de um debate que transcorria entre Fernando Henrique Cardoso e Maria Sylvia de Carvalho Franco - e, de modo óbvio, mas indireto, também a Florestan Fernandes ${ }^{16}$ - sobre a categoria "patrimonialismo". Vale lembrar, contudo, que Fernandes já tinha se debruçado sobre o mesmo problema da "desfaçatez", decerto incontornável dada a crônica irresponsabilidade social e histórica das camadas dominantes no país, porém acionando outros termos e recursos. Na primeira metade da década de I960, já no refluxo de seu protagonismo durante a Campanha em Defesa da Escola Pública - na qual atuou como um dos principais, se não o principal, intelectual público, com forte inscrição nos debates veiculados na imprensa (SAVIANI, I996) -, e retomando os materiais da pesquisa sobre relações raciais em São Paulo para a defesa de sua tese de cátedra, Fernandes mobilizou de modo central a categoria "dilema”,

I5 O ensaio foi publicado, originalmente, na revista Les temps modernes, dirigida por Jean-Paul Sartre, no início da década de I970, momento no qual Roberto Schwarz se encontrava no exílio, em Paris (BUENO, 2008).

I6 A esse respeito, cf. Botelho, 2013. 
acionada para descrever os obstáculos estruturais e dinâmicos à plena efetivação de uma ordem democrática no contexto brasileiro (BRASIL JR., 20I3).

Conforme a interpretação de Gabriel Cohn (I986), a noção de "dilema" remete a mais um problema clássico da sociologia weberiana, que é o das opções que se abrem aos agentes sociais em determinada constelação histórica. No caso de Fernandes, os “dilemas" são pensados em conjugação com os "padrões" (seguindo ainda aqui a interpretação de Cohn), que tem a ver com os princípios de organização social que imprimem ritmo e sentido aos processos sociais. Os padrões básicos, no caso, são os da "ordem social competitiva" (termo de Fernandes), que, ao contrário de uma "ordem social estamental”, baseada na monopolização da renda, do prestígio social e do poder político, teria o potencial de abrir suas principais posições sociais à competição - quer dizer, os diferentes grupos, dotados de direitos e garantias sociais mínimas, teriam a possibilidade de disputar os principais recursos socialmente disponíveis. No caso brasileiro, de acordo com a pesquisa que resultará em A integração do negro na sociedade de classes - e que será crucial para as principais inovações teóricas de Fernandes ${ }^{\mathrm{T} 7}$-, o modo de organização da "ordem social competitiva" não conheceria plena eficácia na coordenação das relações sociais, combinando-se estruturalmente com o padrão social anterior, legado do "antigo regime" (outro termo de Fernandes). Ora, isso caracterizaria uma série de "dilemas", pois o modo pelo qual se deu o processo de expansão e consolidação da "ordem social competitiva" no Brasil atualizaria permanentemente os "obstáculos à realização daquilo que seja próprio a essa forma de organização" (COHN, I986, p. I4I), notáveis sobretudo na "ausência de uma burguesia, do burguês como tipo social capaz de desempenhar adequadamente os papéis que o padrão de [...] uma ordem social competitiva [...] exige para sua plena efetivação" (COHN, I986, p. I42-I43).

Bem entendido, o ponto de Fernandes não é a ausência de setores propriamente burgueses no país, mas de um padrão de conduta desses setores que não enfrenta ativamente os "dilemas" postos pela sociedade brasileira, isto é, que não dinamiza "para a frente" a ordem social de modo a saturar historicamente (mais uma expressão do autor) os potenciais civilizatórios nela inscritos. Isso conduziria Fernandes a um tipo de análise em que a reconstrução do processo social se combina a uma espécie de avaliação ética, na aparência "quase moralista" (COHN, I986, p. I45), mas que no fundo persegue os mecanismos pelos quais, nessa "conjugação entre atores e oportunidades", a sociedade acaba por engendrar e conduzir a "posições de mando, a posições decisivas", não o "burguês empreendedor, mas mais propriamente o oportunista" - resultando em um "processo que no final das contas vai aprofundar, mais do que resolver, os dilemas com que se defronta esse tipo de ordem social” (COHN, I986, p. I46). Trocando em miúdos, a efetivação do padrão societário exige uma tomada de decisão, uma opção coletiva que enfrente diretamente os obstáculos; porém, o agente típico selecionado socialmente para tal (o burguês) não se mostra capaz de enfrentá-los - este é o núcleo duro da noção de "dilema" em Florestan Fernandes.

Um dos planos em que se manifesta o "dilema" nos modos de agir coletivamente dos setores burgueses no Brasil, e que tem uma nítida afinidade com os temas da

I7 Para uma análise das principais inovações teóricas contidas nas pesquisas de Fernandes sobre as relações raciais no país, cf. Bastos, 20I5; Cohn, 2015. 
"volubilidade" e da "desfaçatez de classe" em Schwarz, é o do descompasso entre os valores manifestados e as formas efetivas da conduta social. Fernandes destaca, em texto escrito no contravapor da derrota da campanha pela escola pública pelos setores conservadores, a existência de "um tipo de inconsistência estrutural e dinâmica que nasce da oposição entre o comportamento social concreto e os valores básicos de determinada ordem social” (FERNANDES, I976, p. 208). Esse seria o caso da adesão aos fundamentos morais da civilização burguesa por parte das camadas sociais dominantes. Tal adesão não passaria, a rigor, de uma forma apenas epidérmica e superficial daqueles valores, a qual não levaria às últimas consequências as exigências da "ordem social competitiva”. A despeito da verbalização de compromissos "progressistas", o comportamento profundo dos agentes sociais continuaria se pautando em direção contrária à efetiva democratização da sociedade. Aqueles compromissos seriam simples "racionalizações", ou, nos termos do autor:

O comportamento pode manter-se fiel a modelos arcaicos e tradicionalistas; a verbalização que dele faz o homem eleva-se a outro nível, como se o agente social fosse guiado por outros incentivos e motivações. Daí toda uma mitologia do progresso, da modernização tecnológica e do liberalismo, que condensa uma infinidade de manifestações simbólicas compensatórias, cuja função é sempre a mesma; dar-nos segurança no plano da afirmação coletiva de comunidade nacional. (FERNANDES, I976, p. 209).

Um mecanismo análogo, destinado a destituir de eficácia prática as verbalizações pretensamente "democráticas" por parte dos setores burgueses, se manifestaria com grande nitidez no plano das relações raciais, especialmente no funcionamento do chamado "mito da democracia racial". A aparência de uma sociedade aberta indistintamente a brancos e negros, como se não houvesse bloqueios sistemáticos no acesso a direitos e garantias mínimas para a população negra, caminhava a par com a presença lábil, mas não menos sistemática, de comportamentos racistas e práticas discriminatórias - eis um dos pontos de chegada da análise de A integração do negro. O funcionamento do "mito" revelaria, portanto, uma espécie de hipocrisia estrutural presente na sociedade brasileira, particularmente sensível na autocomplacência com que os brancos buscavam "salvar as aparências" democráticas em meio à enorme tolerância com o preconceito racial. A passagem abaixo, um pouco longa, condensa o argumento de Fernandes a este respeito em A integração:

Na verdade, os “brancos” aderem a uma ética mascarada, em grande parte, porque ainda estão sob o domínio do padrão tradicionalista e assimétrico de relação racial. Não há outra explicação para os fatos registrados, que revelam: Io - sua extrema insensibilidade - diante dos dramas humanos provocados pelas práticas discriminativas; em face das contradições indisfarçáveis entre a estereotipação negativa e os conflitos de padrões ideais da cultura; e ante as inconsistências visíveis das atitudes, avaliações e comportamentos raciais, herdados do passado, e os fundamentos axiológicos, compartilhados conscientemente, da ordem social competitiva; $2^{\circ}$ - sua extrema tenacidade - na defesa e na perpetuação, no plano etológico, do padrão tradicionalista de relação racial, pela qual incrementam, pelas formas possíveis, a alienação moral do "negro" 
(o que está por trás de disposições do tipo "preto não é gente", "é preciso pôr o preto no seu lugar", "o negro não tem cabeça para se governar” etc. - senão a autonomia moral do "branco" e a mais completa heteronomia moral do "negro"?); $3^{\circ}$ - sua extrema autocomplacência - patente no empenho de "salvar-se as aparências" (o que canaliza a crítica ou a fúria não contra o preconceito ou a discriminação, mas contra a sua manifestação ostensiva) - alimenta uma espécie de farisaísmo exemplar, francamente tolerante ao comércio com o "preconceito de cor".

[Eis o] campo confinado da revolução do horizonte moral. Esta tende a se operar com intensidade crescente. Mas encontra uma barreira na ausência de entusiasmo com que os critérios da ordem social competitiva são aplicados ou impostos às relações raciais. Há os que perfilham desaprovações virulentas - e que representam o "preconceito de cor" como "nódoa imunda", "coisa estúpida”, "comportamento indigno de gente civilizada" etc. Contudo, tais verbalizações não impedem, em situações concretas, que seus agentes tomem decisões morais ambíguas e por vezes chocantemente contraditórias. (FERNANDES, 2008a, p. 530-53I).

Essa relação vacilante com os valores civilizatórios por parte dos setores burgueses no Brasil - mecanismo que contribuiu, ao lado de outros, para um processo de mudança social que reatualiza continuamente, ainda que em níveis crescentes de complexidade societal, o subdesenvolvimento da sociedade brasileira - foi depois retrabalhada por Florestan Fernandes em A revolução burguesa no Brasil (I975), em particular na análise das "polarizações ideológicas e utópicas” do liberalismo entre nós. Como não teremos espaço para desenvolver essa questão aqui - que, aliás, configura um campo de comparações com as interpretações de Schwarz sobre o liberalismo no século XIX, salvo engano ainda não explorado pela literatura especializada -, queremos apenas frisar que a noção de "dilema”, e sua correlata hipocrisia estrutural (Fernandes usa o termo "farisaísmo exemplar"), remete a uma espécie de versão alternativa e anterior da "desfaçatez de classe” tão bem caracterizada por Schwarz em sua análise dos romances machadianos. Não se trata, é claro, de considerar essas formulações de Fernandes recursos fundamentais dos argumentos que seriam desenvolvidos anos depois por Schwarz, pois não temos evidências textuais a respeito - ao contrário do debate entre Cardoso e Franco, reconhecido pelo próprio crítico como fundamentais para suas teses ${ }^{18}$. Mas a noção de "dilema", proposta por Fernandes, indica, de um lado, que o arco de problemas levantados pela noção de "desfaçatez de classe" já conhecia certo acúmulo nos trabalhos da Cadeira de Sociologia I da USP e, de outro, que essas formulações alternativas - a de Fernandes e a de Schwarz - levam a implicações distintas. Senão, vejamos.

Schwarz, é verdade que escrevendo já em outro contexto histórico, e mobilizando igualmente o "pessimismo" frankfurtiano, localiza a “desfaçatez de classe” e a

I8 Como sugerido por Lidiane Rodrigues (20II, p. 466), a respeito das possíveis relações de Schwarz com a tese de Fernandes: "Schwarz cita, apropria-se, desenvolve as sugestões dela e é tão difícil encontrar registro seguro da influência que possivelmente tenha recebido d'A integração do negro na sociedade de classes quanto é fácil imaginá-lo: por meio do seminário com seus ledores e assistentes, conversas com Antonio Candido, buchichos pós-defesas, típicos, mesmo quando a prática delas começa a ser rotinizada”. 
irresponsabilidade coletiva dos "de cima" como elementos fundamentais da marcha grotesca do capital na periferia do capitalismo, que daria uma margem de arbítrio e violência aos proprietários, impensáveis (talvez) em latitudes mais civilizadas, dando uma conotação ainda mais desalentadora ao processo histórico de neutralização dos impulsos de negação da ordem social. Já Fernandes, em sua reconstrução "quase moralista”, para retomarmos a provocação de Gabriel Cohn, da responsabilidade histórica dos agentes sociais, sinaliza em seus textos - e isso é particularmente notável em seus estudos sobre a questão racial - para a difícil (e talvez mesmo improvável) emergência do "Povo" (assim, em maiúscula) na cena histórica (FERNANDES, 2008b), que, no entanto, teria a função de levar a sério os valores civilizatórios e politicamente vencer o "antigo regime". Quer dizer, a despeito da estreita margem de atuação das camadas populares - afinal, seriam os setores mais vulneráveis da sociedade aqueles que perseguiriam com maior denodo os compromissos com os valores da ordem democrática, outro ponto de chegada de $A$ integração do negro na sociedade de classes -, caberia a eles a ruptura com a hipocrisia estrutural da sociedade brasileira e a promoção de alguma sorte de curto-circuito no interior do circuito fechado da dominação burguesa (FERNANDES, 20I4).

\section{CONSIDERAÇõES FINAIS}

Procuramos esboçar, ao longo deste artigo, as raízes do princípio formal da volubilidade, destacado pela leitura que Roberto Schwarz efetuou do romance Memórias póstumas de Brás Cubas, de Machado de Assis. De um lado, tentamos proceder a uma leitura a contrapelo da própria interpretação de Schwarz sobre suas referências sociológicas, mostrando como a divergência entre Franco e Cardoso talvez tenha sido mais decisiva do que as possíveis convergências entre suas interpretações do Brasil para a construção do diagnóstico da volubilidade. Buscamos sugerir ainda, a despeito da distância sempre aventada pelo crítico literário em relação a Florestan Fernandes, que a categoria "dilema" pode ser lida como uma formulação aparentada, embora com recursos e implicações bem distintos, da "desfaçatez de classe" discutida longamente na análise de Schwarz das Memórias póstumas de Brás Cubas.

Essas posições assumidas por Schwarz ganham igualmente ressonância nos modos pelos quais o crítico entende a mudança da sociedade brasileira dos Oitocentos até o presente: na chave das permanências. Aqui, mais uma vez, a interpretação do Brasil formalizada por Schwarz guarda bastante proximidade com o tipo de reflexão proposto por Franco, mais sensível aos nexos de permanência que às transformações estruturais - à diferença, portanto, de Fernandes e Cardoso, que, em diferentes registros, anotaram os obstáculos à mudança $a^{\text {I9 }}$. Se lembrarmos da entrevista concedida por Schwarz ao jornal Folha de S. Paulo, intitulada "Agregados

I9 Para o caso de Franco, André Botelho (20I3, p. 362) observa: "As assertivas de Maria Sylvia de Carvalho Franco em estudos posteriores sobre a perenidade do seu diagnóstico sobre a sociedade brasileira em conjunturas históricas tão diferentes daquela do seu estudo empírico original, [...] [como] nos muitos artigos de conjuntura política sobre o Brasil contemporâneo, que vem publicando na grande imprensa, [...] [implicam uma visão em que a] realidade social parece deixar de ser um processo dinâmico e se torna um estado constante". 
antigos e modernos" (2007), podemos observar como sua reflexão tende mesmo a pensar diacronicamente os desdobramentos do processo social na chave das permanências. Para o crítico, a situação dos despossuídos de nossos dias guardaria estreita relação com o passado colonial, mais precisamente, com a situação dos agregados e dependentes da sociedade escravocrata, ao continuarem excluídos do processo produtivo e sem acesso à cidadania plena (SCHWARZ, 20I2a). Como bem mostra Fabio Mascaro Querido (2013), o livro Martinha versus Lucrécia - no qual a entrevista "Agregados antigos e modernos" figura - seria representativo de uma crítica dialética forjada em estreita relação com o tempo presente, atenta à dinâmica contraditória dos desdobramentos do capitalismo na contemporaneidade.

Ou seja, a leitura levada a cabo por Roberto Schwarz dos romances de Machado de Assis, em particular, de Memórias póstumas de Brás Cubas, aqui enfatizado, não se esgota no Brasil oitocentista, uma vez que a volubilidade pode ser relacionada, como vimos, à dinâmica conservadora da modernização levada a cabo no país. Para falarmos novamente com Querido (20I3, p. 233), o pensamento de Roberto Schwarz, ao não deixar de dialogar jamais com a nossa contemporaneidade, permite não somente a revitalização da teoria crítica, mas "o alargamento do horizonte político das classes subalternas no Brasil e no mundo, que ainda aguardam, a partir dos múltiplos focos de lutas de resistência [...] um novo despertar histórico". Com essa perspectiva, não à toa podemos dizer que o crítico, assim como Florestan Fernandes, também volta a sua atenção para a situação dos egressos da escravidão, cuja integração à sociedade ainda não se processou de modo efetivo, tornando-os parte constitutiva da camada de "sujeitos monetários sem dinheiro", o que o famoso romance de Paulo Lins, Cidade de Deus (I997), revelaria com toda a clareza (SCHWARZ, I999b).

\section{SOBRE OS AUTORES}

KARIM HELAYEL é doutorando no Programa de Pós-Graduação em Sociologia e Antropologia da Universidade Federal do Rio de Janeiro (PPGSA/UFRJ). E-mail: khelayel@gmail.com https://orcid.org/o0oo-0002-5680-4556

ANTONIO BRASIL JR. é professor do Departamento de Sociologia e do PPGSA/UFRJ. E-mail: antoniobrasilir@gmail.com https://orcid.org/oooo-oooI-8653-668X 


\section{REFERÊNCIAS}

ARANTES, P. Sentimento da dialética na experiência intelectual brasileira: dialética e dualidade segundo Antonio Candido e Roberto Schwarz. Rio de Janeiro: Paz e Terra, I992.

ARAÚJO, R. B. Guerra e paz: Casa-grande ersenzala e a obra de Gilberto Freyre nos anos 30. São Paulo: Editora 34, 2005. BASTOS, E. Pensamento social da Escola Sociológica Paulista. In: MICELI, S. (Org.). O que ler na ciência social brasileira, I970-2002. v. IV. São Paulo: Anpocs/Ed. Sumaré; Brasília, DF: Capes, 2002.

As criaturas de Prometeu: Gilberto Freyre e a formação da sociedade brasileira. São Paulo: Global, 2006. . Sessenta anos da publicação de um relatório exemplar. Sinais Sociais, v. Io, n. 28, 20I5, p. 29-54.

BENJAMIN, W. (I940). Sobre o conceito da história. In: . Magia e técnica, arte e política: ensaios sobre literatura e história da cultura. Obras escolhidas I. São Paulo: Brasiliense, I994.

BOTELHO, A. Teoria e história na sociologia brasileira: a crítica de Maria Sylvia de Carvalho Franco. Lua Nova, São Paulo, n. 90, 2013, p. 33I-366.

BRASIL JR., A. Passagens para a teoria sociológica: Florestan Fernandes e Gino Germani. São Paulo: Hucitec, 2013. BRITO, L. O. B. de. Marxismo como crítica da ideologia: um estudo sobre os pensamentos de Fernando Henrique Cardoso e Roberto Schwarz. Tese (Doutorado em Ciência Política). Programa de Pós-Graduação em Ciência Política, Faculdade de Filosofia, Letras e Ciências Humanas, Universidade de São Paulo, 20I9. BUENO, A. O arcaico e o moderno no Brasil: variações em torno de uma educação interrompida. Trabalho, educação e saúde, v. 6, n.2, out. 2008, p. 259-282.

CANDIDO, A. O discurso e a cidade. Rio de Janeiro: Ouro sobre Azul, 2010.

CARDOSO, F. H. (I962). Capitalismo e escravidão no Brasil meridional: o negro na sociedade escravocrata do Rio Grande do Sul. Rio de Janeiro: Paz e Terra, I997.

CAZES, P. A sociologia histórica de Maria Sylvia de Carvalho Franco: pessoalização, capitalismo e processo social. Dissertação (Mestrado em Sociologia). Programa de Pós-Graduação em Sociologia e Antropologia, Instituto de Filosofia e Ciências Sociais, Universidade Federal do Rio de Janeiro, 2013.

CEVASCO, M. E.; OHATA, M. (Org.). Um crítico na periferia do capitalismo: reflexões sobre a obra de Roberto Schwarz. São Paulo: Companhia das Letras, 2007.

CEVASCO, M. E. Modernização à brasileira. Revista do Instituto de Estudos Brasileiros, São Paulo, n. 59, dez. 20I4, p. I9I-2I2.

COHN, G. Padrões e dilemas no pensamento de Florestan Fernandes. In: MORAES, R. et al. Inteligência brasileira. São Paulo: Brasiliense, I986.

. A margem e o centro: travessias de Florestan Fernandes. Sinais Sociais, v. Io, n. 28, maio-agosto, 20I5, p. II-28.

FAORO, Raymundo. Machado de Assis: a pirâmide e o trapézio. 4. ed. rev. São Paulo: Globo, 2001.

FRANCO, M. S. C. (I969). Homens livres na ordem escravocrata. São Paulo: Ed. Unesp, I997.

FERNANDES, F. A sociologia numa era de revolução social. 2. ed. Rio de Janeiro: Zahar, I976. . (I975). A revolução burguesa no Brasil: ensaio de interpretação sociológica. São Paulo: Globo, 2005. . (I965). A integração do negro na sociedade de classes: no limiar de uma nova era. v. 2. São Paulo: Globo Livros, 2008a.

. A integração do negro na sociedade de classes: o legado da raça branca. v. I. São Paulo: Globo Livros, 2008b. . Circuito fechado. São Paulo: Globo Livros, 20I4.

HELAYEL, K. O favor e a sociedade brasileira: a interpretação de Roberto Schwarz. Dissertação (Mestrado). Programa de Pós-Graduação em Sociologia e Antropologia, Universidade Federal do Rio de Janeiro, 2015. . Teoria, história e comparação na sociologia de Fernando Henrique Cardoso. Paper apresentado no $42^{\circ}$ Encontro anual da Anpocs, 2018. 
HOELZ, M. Homens livres, mundo privado: violência e pessoalização numa sequência sociológica. Dissertação (Mestrado). Programa de Pós-Graduação em Sociologia e Antropologia, Universidade Federal do Rio de Janeiro, 2010.

LINS, P. Cidade de Deus. São Paulo: Companhia das Letras, I997.

LÖWY, M. Walter Benjamin: aviso de incêndio - uma leitura das teses “Sobre o conceito de história”. São Paulo: Boitempo, 2005.

MELO, A. C. B. "Pressupostos, salvo engano, de uma divergência silenciosa: Antonio Candido, Roberto Schwarz e a modernidade brasileira”. Alea, v. I6, n. 2, 2014, p. 403-420.

MOURA, F. R. de. Um crítico no redemoinho. Tempo Social, v. 3, n. 2, 20II, p. 7I-99.

OHATA, M. Ascensão à brasileira. In: CEVASCO, M. E.; OHATA, M. (Org.). Um crítico na periferia do capitalismo: reflexões sobre a obra de Roberto Schwarz. São Paulo: Companhia das Letras, 2007.

QUERIDO, F. Colapso da modernização: Roberto Schwarz e a atualização da dialética à brasileira. Novos Estudos, n. 97, 2013, p. 227-233.

. Pensamento ao quadrado: Roberto Schwarz e o Brasil. Lua Nova, São Paulo, n. I07, 20I9, p. 235-26I.

RAMASSOTE, R. A formação dos desconfiados: Antonio Candido e a crítica literária acadêmica (I96I-I978). Dissertação (Mestrado). Departamento de Antropologia Social, Instituto de Filosofia e Ciências Humanas, Universidade Estadual de Campinas, 2006.

RICUPERO, B. O lugar das ideias: Roberto Schwarz e seus críticos. Sociologia e Antropologia, v. 3, n. 6, novembro, 20I3, p. 525-556.

RODRIGUES, L. S. A produção social do marxismo universitário em São Paulo: mestres, discípulos e "um seminário” (I958-I978). Tese (Doutorado em História). Programa de Pós-Graduação em História Social, Universidade de São Paulo, São Paulo, 20II.

SAVIANI, D. Florestan Fernandes e a educação. Estudos Avançados, v. Io, n. 26, I996, p. 7I-87.

SCHWARZ, R. (I977). Duas meninas. São Paulo: Companhia das Letras, I997. .Um seminário de Marx. In: . Sequências brasileiras: ensaios. São Paulo: Companhia das Letras, I999a.

. Cidade de Deus. In: . Sequências brasileiras: ensaios. São Paulo: Companhia das Letras, I999b. . Ao vencedor as batatas. São Paulo: Duas Cidades/Ed. 34, 2000 .

. (I990). Um mestre na periferia do capitalismo: Machado de Assis. São Paulo: Duas Cidades/Ed. 34, 200ob.

. (I970). Cultura e política, I964-I969. In: . O pai de família e outros estudos. São Paulo: Companhia das Letras, 2008a.

. Ao vencedor as batatas 30 anos: crítica da cultura e processo social. Entrevista com Roberto Schwarz a Lília Schwarcz e André Botelho. Revista Brasileira de Ciências Sociais, v. 23, n. 67, junho, 2008b, p. I47-I94.

. Roberto Schwarz (Entrevista). In: Montero, P. \& Moura, F. Retrato de grupo - 40 anos do Cebrap. São Paulo: Cosac Naify, 2009, p. 227-245.

. (2007). Agregados antigos e modernos. In: . Martinha versus Lucrécia: ensaios e entrevistas.

São Paulo: Companhia das Letras, 20I2a, p. I73-I83.

. Na periferia do capitalismo (Entrevista). In: . Martinha versus Lucrécia: ensaios e entrevistas.

São Paulo: Companhia das Letras, 2012b, p. 280-304.

WAIZBORT, L. A passagem do três ao um. São Paulo: Cosac Naify, 2007.

. Roberto Schwarz: entre forma literária e processo social. In: BOTELHO, A.; Schwarcz, L. M (Org.).

Um enigma chamado Brasil. São Paulo: Companhia das Letras, 2009.

WEBER, M. Economia e sociedade. Brasília: Editora UnB, I999. 